\title{
1 Multispectroscopic methodology to study Libyan Desert Glass and its
}

\section{formation conditions}

\author{
Leticia Gomez-Nubla ${ }^{1}$, Julene Aramendia ${ }^{1}$, Silvia Fdez-Ortiz de Vallejuelo ${ }^{1}$, Ainhoa \\ Alonso-Olazabal ${ }^{2}$, Kepa Castro ${ }^{1}, \mathrm{M}^{\mathrm{a}}$ Cruz Zuluaga ${ }^{2}$, Luis Ángel Ortega ${ }^{2}$, Xabier \\ Murelaga $^{3}$, Juan Manuel Madariaga ${ }^{1}$ \\ ${ }^{1}$ Department of Analytical Chemistry, Faculty of Science and Technology, University of the \\ Basque Country UPV/EHU, P.O.Box 644, 48080 Bilbao, Spain \\ ${ }^{2}$ Department of Mineralogy and Petrology, Faculty of Science and Technology, University of \\ the Basque Country UPV/EHU, P.O.Box 644, 48080 Bilbao, Spain \\ ${ }^{3}$ Departament of Stratigraphy and Palaeontology, Faculty of Science and Technology, \\ University of the Basque Country UPV/EHU, P.O.Box 644, 48080 Bilbao, Spain
}

*Address correspondence to leticia.gomez@ehu.eus (L. Gómez-Nubla), silvia.fernandez@ehu.eus (S. Fdez-Ortiz de Vallejuelo)

\section{Abstract}

The Libyan Desert Glass (LDG) is a melt product whose origin is still a matter of controversy. With the purpose of adding new information about this enigma, the present paper analyzes the inner part of the LDG specimens and compares it with the results of the LDG surfaces. An integrated analytical methodology was used combining different techniques such as Raman spectroscopy, in point-by-point and imaging modes, Scanning Electron Microscopy with X-ray microanalysis (SEM-EDS), EnergyDispersive Micro X-ray Fluorescence spectrometry ( $\mu$-EDXRF), Electron Probe Micro Analyzer (EPMA) and optical cathodeluminescence (Optical-CL). According to our 
results, flow structures of the melt and the amorphous nature of the matrix could be discerned. Moreover, the observed displacement of the Raman bands, such as the cases of quartz and zircon, and the identification of certain compounds such as coesite (the most clarifying phase of high pressures), $\alpha$-cristobalite, gypsum, anhydrite, corundum, rutile, amorphous calcite, aragonite and calcite allowed us to know that LDGs could be subjected to shock pressures between 6 and more than $30 \mathrm{GPa}$, and temperatures between 300 and $1470^{\circ} \mathrm{C}$. The differences of temperature and pressure would be provoked by different cooling process during the impact. Besides, in most cases the minerals corresponding to high pressure and temperatures were located in the inner part of the LDGs, with some exceptions that could be explained because they were trapped subsequently to the impact; there was more than one impact or heterogeneous cooling.

Furthermore, nitrogen and oxygen gases were identified inside bubbles, which could have been introduced from the terrestrial atmosphere during the meteorite impact. These data helped us to clarify some clues about the origin of these enigmatic samples.

KEYWORDS: Libyan Desert Glass; impact melt; mineralogy; analytical methodology.

\section{INTRODUCTION}

Libyan Desert Glass (LDG) is an enigmatic type of impact glass that was firstly documented by Patrick A. Clayton in 1933. Clayton and Spencer first published a scientific report on LDG that led to its official discovery [1]. Since then, many field expeditions have been carried out and more than 200 tonnes of LDG have been collected [2]. They are scattered over an area of $6500 \mathrm{~km}^{2}$ located in north -south- 
trending inter-dune channels between the Great Sand Sea and the Gilf Kebir Plateau around the Western Desert of Egypt, near the Libyan border [2-4]. They are mainly concentrated in two zones: a larger ring-shaped area in the south and a smaller oval area in the north [2]. These lithologies are of the Cretaceous Nubian Formation outcrop. Similarities between these sandstones and the LDG composition should clarify the fusion of the ground material. However, the lithologic variation of these sandstones makes difficult to identify them as the origin of LDGs $[5,6]$. LDGs were found to a depth of $\sim 2 \mathrm{~m}$, and the deeper they are located, the bigger they are [7]. Their weight goes from less than $1 \mathrm{~g}$ up to over $25 \mathrm{Kg}$ [2]. Its formation age was determined by fission track analysis, which indicated ranges from $28.5 \pm 2.3$ to $29.4 \pm 0.5$ My [8]. The distribution of LDG fragments could be the result of fluvial transport that occurred throughout the Oligocene boundary, where there was a humid climate with high quantity of precipitation in lacustrine environment or coastal seawater [9-11]. In general, LDG is a compact hard glassy rock, transparent, yellowish or greenish, sometimes dark or milky. Chemically, bulk LDG has concentrations of approximately $98 \mathrm{wt} \% \mathrm{SiO}_{2}$ [12]. In addition, it can have other compounds. It usually contains air bubbles, cristobalite inclusions and dark or brown inclusions appearing as streaks, ribbons, misty waves or simply solid spots, possibly derived by melting or decomposition of iron oxides. The concentrations of components are highly variable. Inclusion grain sizes can vary between 0.1 to $0.3 \mathrm{~mm}$ in diameter, occasionally up to 1 $\mathrm{mm}[2-4,13]$.

The origin of LDG is controversial and there are two main theories among other hypothesis. One of them states that its genesis is related to an impact of an extraterrestrial body into the sedimentary materials causing its fusion [7, 14]. The second one considers the formation of LDG as the result of a low-altitude explosion of 
an extraterrestrial body in the atmosphere, generating a thermal pulse (airburst) and causing the melting of surface $[15,16]$. Both theories have been instilled with numerous non-conclusive experimental results. The impact origin of the LDG is supported by the presence of schlieren structures, planar deformation features, partly digested mineral phases, high pressure-temperature mineral phases and non-crystalline phases formed during shock metamorphism. In addition, abundance patterns of platinum-group elements ( $\mathrm{Ru}, \mathrm{Rh}, \mathrm{Pd}$, Os, Ir, and $\mathrm{Pb}$ ), a reduced state of iron-rich portions, graphite-rich bands in the glasses, iridium content and, finally, osmium $\left({ }^{187} \mathrm{Os} /{ }^{188} \mathrm{Os}\right)$, strontium $\left({ }^{87} \mathrm{Sr} /{ }^{86} \mathrm{Sr}\right)$, argon $\left({ }^{40} \mathrm{Ar} /{ }^{36} \mathrm{Ar}\right)$ and neodymium $\left({ }^{143} \mathrm{Nd} /{ }^{144} \mathrm{Nd}\right)$ isotopic ratio values have been regarded as the fingerprints of the supposed primitive meteoritic matter in the LDGs [2, 4, 6,17-20].

To confirm both theories, a crater should be localized in the area. However, the location of such a crater is difficult to resolve because it would be covered by the Great Sand Sea desert or it would be destroyed by erosion $[4,16]$. Despite this fact, the existence of the geoform called Kebira has been considered as possible crater and source of LDGs [7]. Nevertheless, the study of the crater concluded that the impact probably happened 100 million years ago approximately [21] and the LDG was formed 28.5 million years ago, therefore they would not coincide in time as LDGs are younger. In spite of the controversy, a greater number of scientists came to terms with the origin of the LDGs caused by an impact of an extraterrestrial body over the sand or sandstone, which would be deposited in lacustrine environment or coastal seawater, the fusion of material with the meteoritic component and its subsequent solidification $[5,7,12,14]$

This work aims to find new experimental evidences following a multispectroscopic methodology, looking at the mineralogy of the matrix, inclusions, 
cavities and bubbles in the internal and external parts of LDG specimens to ascertain the formation conditions (mainly temperature and pressure) of the identified compounds. With all the collected information, it is possible to obtain more evidence about the origin of this enigmatic material.

\section{MATERIAL AND METHODS}

\subsection{Samples and sample preparation}

Several specimens of LDG from the Meteorites Collection of the Basque Country University (UPV/EHU) were analyzed in order to achieve the mentioned objectives. The dimensions of the samples varied between $1-5 \mathrm{~cm}$ in length and $2-4 \mathrm{~cm}$ in width, whereas their weight varied between 5-23 g. The analyzed LDGs were translucent glassy samples. Some types of inclusions could be macroscopically discerned: dark, brownish and whitish spheres.

The samples were sliced, and then, thick and thin sections were prepared to detect differences between the surface and the inner part of the LDGs. The inner part is better preserved since it has not been in contact with the environment. A BuehlerPetroThin sectioning system with a diamond saw was employed. As a perfectly flat surface free of deformations is necessary, the fragments were polished using silicon carbide powder of different grain size on frosted glasses. The thickness of the fragments was approximately $800 \mu \mathrm{m}$. Once the flat surface was obtained, in the case of the thin sections, samples were mounted on glass slides (dimensions of $27 \times 46$ x $1.5 \mathrm{~mm}$ ) with an epoxy resin (composed of polyurethane, acrylic and cyanoacrylate) and then, the samples were smoothed using progressively finer abrasive grit until they were only 30 $\mu \mathrm{m}$ thick. 
After the lamination of the samples, the majority of the mentioned brownish

inclusions could not be discerned. However, whitish crystals with round shape were predominant. Single embedded minerals and bubbles were observed by optical microscope. More than 300 inclusions, around 200 crystalline forms in the matrix and more than 30 bubbles were analyzed in the different LDG specimens.

\subsection{Analytical methods}

Several analytical techniques were used throughout this work. Optical microscopy was performed with a NIKON optical polarizing microscope equipped with a digital camera in order to observe the texture and the mineralogy of the melt. In addition, a Technosyn cold-cathode cathodoluminescence stage, model 8200MKII, with a vacuum chamber coupled to a polarizing microscope was used on the thin sections to observe the internal structure of the melt. It worked under standard operating conditions at $12-15 \mathrm{kV}$ of accelerating potential, $0.5-0.6 \mathrm{~mA}$ beam current, and a beam diameter of $4.5 \mathrm{~mm}$.

For the elemental characterization Energy-Dispersive Micro X-ray Fluorescence spectrometry ( $\mu$-EDXRF), Scanning Electron Microscopy with X-ray microanalysis (SEM-EDS) and Electron Probe Micro Analyzer (EPMA) were employed. Due to the size of the studied specimens it was not possible to analyze the external part by SEMEDS. For this reason, the elemental data in these areas were acquired by $\mu$-EDXRF. A $\mu$-EDXRF ArtTax model by Bruker was used. The equipment is composed of an X-ray tube with a Mo anode working at $50 \mathrm{kV}$ voltage and $0.6 \mathrm{~mA}$ current. The X-rays were collimated by a $0.65 \mathrm{~mm}$ diameter tantalum collimator. Light elements were measured under a helium flow. Zr, which is a typical element in the LDG composition, could not be measured by $\mu$-EDXRF because it is also present in the source of the equipment. Moreover, thick and thin sections were analyzed with an EVO 40 Scanning Electron 
Microscope coupled to an X-Max Energy-Dispersive X-Ray spectroscopy equipment.

151 That device was used to acquire electron images, to obtain elemental mappings and to 152 determine semi-quantitatively the elemental composition of the matrix and the inclusions. The SEM images were acquired at high vacuum, employing an acceleration voltage of $20 \mathrm{kV}$ without the need to metalize the samples using a detector of secondary electrons. Besides, a JEOL JSM-6400 SEM with an Oxford Pentafet photon energy instruments Link Isis X-Ray (EDX) system was used. Furthermore, a Cameca SX-100 electron probe microanalyzer (EPMA) was used principally to obtain quantitative elemental data about the matrix in thin sections of LDGs, since this technique allows performing more precise quantitative analysis. The SX-100 is equipped with five wavelength dispersive spectrometers (WDS) (each containing a diffracting crystal), a dispersive energy spectrometer (EDS) and SE, BSE, ABS and cathodoluminescence (CL) detectors. The operating conditions for the samples were $100 \mathrm{nA}$ beam current and $15 \mathrm{kV}$ accelerating voltage with a beam diameter of $0.6 \mu \mathrm{m}, 2 \mu \mathrm{m}$ scan distance and 100 ms acquisition time of X-ray peak per point (10 points per sample were analyzed). was determined using Raman spectroscopy. A Renishaw InVia Raman micro spectrometer, coupled to a DMLM Leica microscope with 5x N PLAN (0.12 aperture), 20x N PLAN EPI (0.40 aperture), 50x N PLAN (0.75 aperture; lateral resolution of 2 $\mu \mathrm{m}$ ) and 100x (lateral resolution of $1 \mu \mathrm{m}$ ) long range objectives, was used with the 514 $\mathrm{nm}$ argon ion excitation laser and the $785 \mathrm{~nm}$ diode excitation laser. The power applied was set at the source at a maximum of $50 \mathrm{~mW}$ while on the sample was always less than $20 \mathrm{~mW}$. The spectra were obtained in the range 3000-100 $\mathrm{cm}^{-1}$, accumulating several scans from each spectrum to improve the signal-to-noise ratio. 
In order to obtain Raman chemical images, the StreamLine technology

175 (Renishaw) was employed. The inVia's motorized microscope stage moves the sample beneath the lens so that the line is rasterized across the region of interest. Data are swept synchronously across the detector as the line moves across the sample, and are read out continuously. Details of the working conditions are given elsewhere [22]. Data acquisition was carried out by the Wire 3.0 software package of Renishaw and the analysis of the results was undertaken by Omnic 7.2 software. The results were interpreted by comparing of the collected Raman spectra with Raman spectra of pure standard compounds of the e-VISARCH and e-VISART Raman spectra databases [23] and with the RRUFF database [24]. based on LDG reported. Besides, it also has little amounts of $\mathrm{K}, \mathrm{Ti}, \mathrm{Ca}, \mathrm{Mn}, \mathrm{Fe}, \mathrm{Al}$ and

All these elements were detected in our elemental analyses. Comparing several $\mu$ -

EDXRF spectra of the inner matrix and the superficial one, the main difference was the relative intensity for some of those elements. Fe, Sr, Ca and Ti presented higher peak areas in the inner matrix than on the surface. In contrast, in their sporadic appearances, $\mathrm{Mn}, \mathrm{Cl}$ and S were more intense on the surface (see Electronic Supplementary Material Table S1).

The molecular composition of the matrix, observed by Raman spectroscopy, did 197 not show differences between the surface and inner part. However, three groups of 
spectra can be seen related to the matrix composition depending on the excitation laser used to obtain the Raman spectra [26].

The first group, obtained with the $785 \mathrm{~nm}$ excitation laser, presented three intense and broad (br) bands at 1374, 1554, and $1636 \mathrm{~cm}^{-1}$. A second type of spectrum, also obtained with the same excitation laser, presented five Raman bands at $1277 \mathrm{vs}$ (very strong), 1382vs, 1517s (strong), $1662 \mathrm{br}$ and $1842 \mathrm{br} \mathrm{cm}^{-1}$; similar to that reported by Swaenen et al. [3]. The third group, obtained with the $514 \mathrm{~nm}$ excitation laser, presented bands at 447br, 602w (weak), 810br, 1061br and 1322br cm${ }^{-1}$ (see Electronic Supplementary Material Fig. S1), which was similar to that published by Swaenen et al. [3], except for the bands located around 480 and $820 \mathrm{~cm}^{-1}$ [3]. The bands in the 1200$1900 \mathrm{~cm}^{-1}$ range of the first two spectra are due to the luminescence emission produced by the effect of the red laser $(785 \mathrm{~nm})$ over transition metals or rare earth element, possibly present in the glassy matrix [4, 27]. These spectral features were not observed with the green laser (514 nm). Thus, those signals in the $1200-1900 \mathrm{~cm}^{-1}$ range were not considered for characterisation purposes.

The last mentioned group of Raman spectra should be considered as the typical LDG matrix spectrum (spectrum A) (see Electronic Supplementary Material Fig. S1). In some occasions, that A spectrum of the matrix varied a little bit showing its Raman bands at 447br, 810br, 956br, 1049br, 1195br and 1630br cm ch $^{-1}$ (spectrum B) (see Electronic Supplementary Material Fig. S1). In our further discussion, we will consider both, A and $\mathrm{B}$ types as the Raman background due to the matrix. The broad band at $447 \mathrm{~cm}^{-1}$ is related to the bending modes of the $\mathrm{Si}-\mathrm{O}-\mathrm{Si}$ bonds within the tetrahedral units. Besides, the weak band around $600 \mathrm{~cm}^{-1}$ (only for A spectrum) is ascribed to Si-O bending vibration modes. The band(s) at $400-600 \mathrm{~cm}^{-1}$ varies with the degree of polymerization of the melt and with the Si-O-Si (and Si-O-Al) bridging bond angles [25]. The band 
near $800 \mathrm{~cm}^{-1}$ involves symmetric motions of Si-O-Si bending while the band in the range $850-1200 \mathrm{~cm}^{-1}$ is associated with symmetric Si-O stretching vibrations. The doublet at 955 and $1052 \mathrm{~cm}^{-1}$ observed in the spectrum B is specific of alkali rich glasses. Finally the band at $1630 \mathrm{~cm}^{-1}$ seems to be related with the presence of $\mathrm{H}-\mathrm{O}-\mathrm{H}$ bonds [3, 28]. Although these last spectra have not been described before, their wavenumbers and the presence of broad bands are related to the amorphous nature of the glass bulk.

EPMA analysis revealed and corroborated distinct and heterogeneous quantitative elemental composition of the melt. The inner part contained $99.2 \pm 0.20$ wt $\% \mathrm{SiO}_{2}$ while the outer decreased to $96.8 \pm 0.20$ wt $\%$; $\mathrm{Al}_{2} \mathrm{O}_{3}$ varied from $0.20 \pm 0.02$ wt $\%$ at the inner part to $2.04 \pm 0.01 \mathrm{wt} \%$ in the outer part. Other minor elements also showed similar variations, $\mathrm{Fe}_{2} \mathrm{O}_{3}$ from $0.01 \pm 0.003$ to $0.22 \pm 0.01$ wt $\%$, $\mathrm{TiO}_{2}$ from $0.018 \pm 0.009$ to $0.51 \pm 0.02 \mathrm{wt} \%$ and $\mathrm{CaO}$ varied from nearly 0 to $0.12 \pm 0.007 \mathrm{wt} \%$ in the inner and the outer part. This heterogeneity in elemental composition of the melt was also detected by cathodoluminescence (see Fig. 1) as previous researches showed [25]. Variations on element contents are reflected on CL images, on the differences in colours and brightness within few microns, according with the highly heterogeneous flow structures of the melt (see images on the right in the Fig. 1). This flow texture as well as compositional variation on silicon and aluminium elements was also discerned in images obtained by SEM/EDS, but not so spectacular as the CL images (see Fig.1).

\subsection{Crystalline forms inside the matrix}

Petrographic studies on thin sections by optical microscope showed that LDG exhibit a holohyaline texture with some minerals occurrence such as aluminium rich tiny crystallites, cristobalites and zircons. SEM observations revealed that these euhedral and skeletal crystallites are dispersed along the matrix. These crystallites were 
generally randomly oriented forming aligned clouds and/or aggregations of crystallites defining flow patterns (see Fig. 2). Moreover, crystallites around $3 \mu \mathrm{m}$ showed skeletal structure (i.e. hollow crystallites) and swallowtail ends similar to typical structures of those formed during rapid crystallization from a melt [29]. They were identified as aluminium rich crystallites with traces of Ti and Fe by SEM/EDS analysis (see Fig. 2.b and c). Besides, these aluminium oxides rich crystallites are related to aluminium rich zones of the glass, according to SEM/EDS analysis (see Fig. 2.b and c). Unfortunately, when analyzing these crystallites by Raman spectroscopy no signal was obtained. variability on size, between $40 \mu \mathrm{m}$ and $300 \mu \mathrm{m}$, were observed by optical microscope dispersed within the silica glass matrix. They are crystals with different shape, circular, ellipsoidal and irregular globules. Some of them exhibit internal cracks and with spheroid bodies similar to grapes. The key mineral phase $\alpha$-cristobalite was identified by Raman spectroscopy in these crystals $\left(\mathrm{SiO}_{2}\right.$, with the two main bands at 230vs and $\left.418 \mathrm{vs} \mathrm{cm}^{-1}\right)$. There was a specific case where zircon $\left(\mathrm{ZrSiO}_{4}\right)$ was detected within a cristobalite inclusion (see Fig. 3a). This fact will be discussed below.

Raman spectroscopy analysis in the surface of the LDG samples determined the following phases: anatase $\left(\mathrm{TiO}_{2}\right.$; main Raman band at $\left.143 \mathrm{~s} \mathrm{~cm}^{-1}\right)$, gypsum $\left(\mathrm{CaSO}_{4} \cdot 2 \mathrm{H}_{2} \mathrm{O}\right.$; Raman bands at $411 \mathrm{w}$ and $\left.1006 \mathrm{w} \mathrm{cm}{ }^{-1}\right)$, coesite $\left(\mathrm{SiO}_{2}\right.$; Raman bands at 270w and 521m cm $\mathrm{m}^{-1}$, its most fundamental vibration [30]) and a microcline feldspar $\left(\mathrm{KAlSi}_{3} \mathrm{O}_{8}\right.$; Raman bands at 328vw, 406w, 513m and 1096vw $\mathrm{cm}^{-1}$ ). Apart from coesite, other minerals were identified as crystals trapped in the inner parts of the matrix, such as shocked zircon $\left(\mathrm{ZrSiO}_{4}\right.$; Raman bands at 351m, 435m, 973vw, 1000vs, 1050w, 1085m and 1140vw cm ${ }^{-1}$; see Fig. 3c), calcite $\left(\mathrm{CaCO}_{3}\right.$; Raman bands at $153 \mathrm{w}$, 
279m, 710w and 1085vs $\left.\mathrm{cm}^{-1}\right)$, amorphous calcite $\left(\mathrm{CaCO}_{3}\right.$; Raman bands at $149 \mathrm{w}$, 260m, 709w and 1080vs cm$\left.{ }^{-1}\right)$ and rutile $\left(\mathrm{TiO}_{2}\right.$; Raman bands at $445 \mathrm{~s}$ and $\left.610 \mathrm{~s} \mathrm{~cm}^{-1}\right)$.

From the molecular point of view, comparing the minerals found in the trapped crystals of both outer and inner parts of the matrix, only coesite appeared in both sides. This is a key mineral, a high pressure polymorph of $\mathrm{SiO}_{2}$, to understand the process of formation of the LDGs. The presence of rutile in the inner part of the matrix and anatase in the outer part of the matrix must be considered also relevant. Moreover, the presence of shocked zircon in the inner parts of the matrix could help to understand the formation process of the LDGs.

\subsection{Inclusions}

\subsubsection{Mineral inclusions}

They are considered minerals trapped within the body of the LDG, like grains in the matrix. Some of these inclusions can be completely contained within another mineral.

The $\mu$-EDXRF measurements showed that these inclusions are defined by the high presence of $\mathrm{Al}, \mathrm{Ca}$ and $\mathrm{Si}$. Furthermore, it was possible to distinguish $\mathrm{Na}, \mathrm{Ti}, \mathrm{V}$, $\mathrm{Mn}, \mathrm{Sr}$ and Fe as minor elements, since they did not appear as often as the previous ones, and $\mathrm{S}$ and $\mathrm{Cl}$ at trace level (they appeared in certain occasions), but with variable peak areas for the different bands as a function of the inclusions. This suggests the presence of several compounds and/or mineral phases in such inclusions.

There are dark brownish mineral inclusions characterized by a higher presence of iron, as it has been reported in literature [26]. In order to study the elemental distribution in these brownish inclusions, several elemental composition mappings as well as semi-quantitative determinations were carried out by SEM-EDS. These analyses corroborate the differences in the elemental composition of the internal and external 
brownish inclusions. In general, $\mathrm{Si}$ is the main element in both but the Fe and Ti signals were systematically increased in the inner ones (Fe: $0.5 \pm 0.025$ wt\% (outer) to $5.9 \pm 0.3$ wt\% (inner); Ti: $0.06 \pm 0.003 \mathrm{wt} \%$ (outer) to $0.1 \pm 0.005$ wt\% (inner)). Fig. 4 shows the SEM image of an inner brownish inclusion formed mainly by $\mathrm{Si}$ and several elements such as $\mathrm{O}, \mathrm{Ca}, \mathrm{Al}$ and Fe. Besides, $\mathrm{Na}, \mathrm{Mg}, \mathrm{P}, \mathrm{Cl}, \mathrm{K}$ and $\mathrm{Ti}$ were detected. The distribution maps for the main elements (the presence of elements is represented in white colour and the absence in black) show correlations among $\mathrm{O}, \mathrm{Si}$ and $\mathrm{Al}$, but also correlations among Fe, $\mathrm{O}$ and $\mathrm{Al}$. Some small areas showed correlations even among Ca, $\mathrm{Al}$ and $\mathrm{O}$.

The Raman spectroscopy analyses on several spots of the different brownish inclusion detected several mineral phases: silica, sulphates, carbonates and oxides. Among them, three compounds having the general silicon oxide form but with different structural configurations were found: $\alpha$-quartz ( $\mathrm{SiO}_{2}$; Raman bands at 205m, 263w, 354w, 398vw, 464vs, 696vw, 806w, 1081w and $1160 \mathrm{vw} \mathrm{cm}^{-1}$ ), a modified $\alpha$-quartz with displaced bands (distorted $\mathrm{SiO}_{2}$; 202m, 261w, 353w, 390vw, 461vs, 693vw, 802w, 1064vw, 1080w and $\left.1159 \mathrm{w} \mathrm{cm}^{-1}\right)$ and $\alpha$-cristobalite $\left(\mathrm{SiO}_{2}\right.$; main Raman bands at 230vs and 418vs $\left.\mathrm{cm}^{-1}\right)$.

Besides, three different calcium sulphate modifications were also discerned depending on the location of the inclusions within the LDG sample: gypsum $\left(\mathrm{CaSO}_{4} \cdot 2 \mathrm{H}_{2} \mathrm{O}\right.$; Raman bands at $411 \mathrm{~m}, 618 \mathrm{vw}, 668 \mathrm{vw}$ and $\left.1006 \mathrm{~m} \mathrm{~cm}^{-1}\right)$ and two forms 317 of anhydrite $\left(\mathrm{CaSO}_{4}\right)$, according to their Raman bands [31]. Anhydrite type II ( $\beta$ $318 \mathrm{CaSO}_{4}$, Raman bands at 417w, 610vw, 626vw, 1018m, 1128vw and 1161w cm $\mathrm{cm}^{-1}$ ), with an orthorhombic structure, stable in the $300-1180^{\circ} \mathrm{C}$ range, was detected in the outer brownish inclusions, together with $\alpha$-quartz. Anhydrite type I ( $\alpha-\mathrm{CaSO}_{4}$; Raman bands at $170 \mathrm{w}, 417 \mathrm{w}, 610 \mathrm{vw}, 628 \mathrm{vw}, 1017 \mathrm{~m}, 1110 \mathrm{w}, 1128 \mathrm{w}$ and $1158 \mathrm{vw} \mathrm{cm} \mathrm{cm}^{-1}$ ), with cubic 
structure, stable at temperatures higher than $1180^{\circ} \mathrm{C}$, was identified in the inner brownish inclusion together with gypsum (overlapping of Raman bands causing a displacement from 628 to $624 \mathrm{~cm}^{-1}$ and from 1017 to $1010 \mathrm{~cm}^{-1}$ ). 1085vs $\left.\mathrm{cm}^{-1}\right)$, aragonite $\left(\mathrm{CaCO}_{3}\right.$; Raman band at 207w, 704w and $\left.1083 \mathrm{~m} \mathrm{~cm}^{-1}\right)$ and magnesite $\left(\mathrm{MgCO}_{3}\right.$; Raman bands at 330w, 739w and $\left.1095 \mathrm{~m} \mathrm{~cm}^{-1}\right)$ were identified. Hematite $\left(\alpha-\mathrm{Fe}_{2} \mathrm{O}_{3}\right.$; Raman bands at 226w, 292m, 410w, 612w and $\left.1300 \mathrm{br} \mathrm{cm}{ }^{-1}\right)$, limonite (FeO(OH).n $\mathrm{H}_{2} \mathrm{O}$; Raman bands at 171w, 208m, 243m, 300s, 399vs, 471br, 551s and $\left.1282 \mathrm{br} \mathrm{cm}^{-1}\right)$, corundum $\left(\alpha-\mathrm{Al}_{2} \mathrm{O}_{3}\right.$; Raman band at $\left.416 \mathrm{~m} \mathrm{~cm}^{-1}\right)$, rutile, anatase $\left(\mathrm{TiO}_{2}\right.$; main Raman band at $143 \mathrm{~s} \mathrm{~cm}^{-1}$ ), cinnabar (HgS; main Raman band at $252 \mathrm{~m} \mathrm{~cm}^{-}$ ${ }^{1}$ ) and carbon were also identified in the inclusions. where the carbon lines in SEM-EDS were not correlated with any other element. Carbon was identified through their main Raman bands at $\approx 1300 \mathrm{br}$ and $\approx 1600 \mathrm{br} \mathrm{cm}^{-1}$. The band at $\approx 1580$ - $1600 \mathrm{~cm}^{-1}$ is assigned as the $\mathrm{G}$ band of the $\mathrm{C}$ (originates from the stretching vibration of $\mathrm{sp}^{2}$ carbon atoms $\mathrm{C}-\mathrm{C}$ ). The band at $\approx 1300 \mathrm{~cm}^{-1}$ is attributed to $\mathrm{D}$ band (from the stretching vibration of $\mathrm{sp}^{3}$ carbon atoms, which induces defects and disorders) [32].

It is worth pointing out that commonly, the composition of these inclusions was not homogeneous and they consisted of more than one compound. As an example of the heterogeneous nature of the inclusions, Fig. 5 shows the Raman image obtained in an inner brownish inclusion, having quartz and calcite as the main mineral phases, together with hematite.

A difference in mineral composition was observed depending on the outer or inner location of brownish inclusions. On the one hand, some mineral phases appeared 
only in outer locations of inclusions such as anhydrite A-II, amorphous carbon, corundum, magnesite and cinnabar. On the other hand, some other compounds were only detected in the inner inclusions such as anhydrite A-I, aragonite (but only in the inclusions near the border), gypsum, hematite, limonite (near the surface), displaced $\alpha$ quartz and rutile. Finally, the normal $\alpha$-quartz, $\alpha$-cristobalite, anatase, calcite and carbon were found in both locations of brownish inclusions.

\subsubsection{Cavities and embedded bubbles}

Cavities are irregular areas observed in the matrix, and bubbles are spherical cavities that could have been vesicles, gaseous or fluids.

Irregular cavities and bubbles were also observed in the LDG matrix by optical microscope and SEM observations. According to optical microscopic and SEM observations (see Fig. 6), some individual grains were observed inside the cavities that could be pyroxenes due to their crystal shape revealed through the SEM microscope.

Correlations among $\mathrm{Fe}, \mathrm{Mg}$ and $\mathrm{Si}$, and among $\mathrm{Al}, \mathrm{K}, \mathrm{Ca}$ and $\mathrm{Si}$ were found in the SEM-EDS elemental distribution maps. To verify their composition, Raman spectroscopy and EPMA analyses were performed. Different kind of silicates were identified by Raman spectroscopy, forsterite $\left(\mathrm{Mg}_{2} \mathrm{SiO}_{4}\right.$; Raman bands at 303w, 430w, 604m, 820s, 854s and $\left.961 \mathrm{~m} \mathrm{~cm}^{-1}\right)$ and enstatite $\left(\mathrm{MgSiO}_{3}\right.$; Raman bands at $231 \mathrm{w}$, 296vw, 336m, 389w, 657s, 678vs and 1005vs $\mathrm{cm}^{-1}$ ) (see Fig. 6). These results confirmed the existence of olivine and pyroxenes in the cavities (forsterite and enstatite). Moreover, tephroite $\left(\mathrm{Mn}_{2} \mathrm{SiO}_{4}\right.$; Raman bands at $811 \mathrm{~m}$ and $\left.843 \mathrm{~m} \mathrm{~cm}^{-1}\right)$ was identified in another cavity.

In addition, there were bubbles, spherical in shape, which suggested the presence of vesicles, gaseous or fluids, but some were empty perhaps due to the slicing process. Some others were still full and in order to ascertain the nature of the materials inside 
372 these bubbles, point-by-point Raman analyses were performed identifying oxygen gas

$373\left(\mathrm{O}_{2}\right.$; Raman band at $\left.1554 \mathrm{w} \mathrm{cm}^{-1}\right)$ [33] and nitrogen gas inside them $\left(\mathrm{N}_{2}\right.$; Raman band at 374 2328 $\mathrm{w} \mathrm{cm}^{-1}$ and 2342 $\mathrm{w} \mathrm{cm}^{-1}$ ) [34] (see Fig. 7). Besides, a Raman band at 2337 w cm ${ }^{-1}$ 375 attributable to stretching mode $\mathrm{C} \equiv \mathrm{N}$ was found [35].

376 All the compounds identified in this work are summarized in Table 1, indicating 377 where they were found in the LDGs samples.

(see Table 1) give us the possibility to extend the knowledge of the LDG formation because some detected minerals are characteristic phases for given temperatures and others for certain pressures.

\section{DISCUSSION}

The identified compounds in the inner and outer parts of the analyzed specimens For example, by Raman spectroscopy it is possible to detect the variation due to pressure and temperature in the structure of the compounds because their common Raman bands are displaced. On the one hand, there are three compounds that give us an idea of the pressures affecting the formation of the LDGs. In some inner inclusions of the LDG samples, the main Raman band of $\alpha$-quartz $\left(464 \mathrm{~cm}^{-1}\right.$ for ambient pressure and temperature) appeared slightly displaced at $461 \mathrm{~cm}^{-1}$ (see Fig. 8). Besides, shifts from 205 to 202, 263 to 261 and 806 to $802 \mathrm{~cm}^{-1}$ were observed as well. That displacement is commonly attributed to molecules of crystalline quartz that have been subjected to shock pressures of at least $26 \mathrm{GPa}$ [36].

The Raman spectrum of zircon observed in the matrix (see Fig. 3b), corroborate the pressure conditions in which these LDGs were formed. The main Raman band of the zircon appeared at $1000 \mathrm{~cm}^{-1}$, which corresponds to a shocked zircon (see Fig. 3c). The change in the position of this main band from $1008 \mathrm{~cm}^{-1}$ for normal zircon (see Fig.3d) 
to $1000 \mathrm{~cm}^{-1}$ means that the original zircon (probably trapped from the surface materials during the impact) was shocked to a pressure of at least or around 20 GPa [25]. The most clarifying phase among the shocked minerals is coesite, which has been found not only in the inner but also in the outer mineral embedded materials. Coesite is a silica polymorph produced at high pressures $(>30 \mathrm{GPa})$ from the $\alpha$-quartz $[37,38]$ and is commonly present in materials from large-scale impact craters [37].

The conditions mentioned above could be acquired by shock metamorphism. Thus, the presence of shocked quartz and zircon, but mainly coesite, is a strong indication of an impact, which can be estimated around 20 GPa.

In comparison with other studies, pressure during impact processes might exceed $10 \mathrm{GPa}$, even up to $50 \mathrm{GPa}$ for dense quartz-rich lithologies [39]. Moreover, the nature of LDG inclusions would speak in favor of high-pressure and high-temperature formation initiated by a meteoritic impact, which would implicate the high quenching temperature [3]. This information would corroborate our results.

On the other hand, mineral phases clearly related to high and low temperature were identified. For example, the displacement of the main Raman band of zircon from 1008 to $1000 \mathrm{~cm}^{-1}$ can occur as a consequence of temperatures higher than $1400^{\circ} \mathrm{C}$ [40] and not only due to high pressures.

The occurrence of $\alpha$-cristobalite is an indirect evidence of a high temperature event. The $\alpha$-quartz phase, which is the low-temperature stable polymorph of $\mathrm{SiO}_{2}$, is converted by heating into $\beta$-cristobalite at $1470{ }^{\circ} \mathrm{C}$. Then, $\alpha$-cristobalite is normally formed during the cooling process from the previously formed $\beta$-cristobalite. Therefore, the presence of $\alpha$-cristobalite indicated the former presence of $\beta$-cristobalite and hence, a temperature greater than $1470{ }^{\circ} \mathrm{C}$ and the following cooling process [7, 9]. 

spectra due to the different structures of its polymorphs [31]. Anhydrite III (A-III either soluble anhydrite or $\gamma-\mathrm{CaSO}_{4}$ ) is formed from hemihydrates above temperatures close to $110^{\circ} \mathrm{C}$. Anhydrite II (A-II either insoluble anhydrite or $\beta-\mathrm{CaSO}_{4}$ ) is formed at approximately $300{ }^{\circ} \mathrm{C}$ and it corresponds to the mineralogical form of normal anhydrite. Finally, anhydrite I (A-I or $\alpha-\mathrm{CaSO}_{4}$ ), is a high temperature form that is stable above $1180{ }^{\circ} \mathrm{C}$ [41], but below $1200^{\circ} \mathrm{C}$ reverts to insoluble anhydrite [41]. In the case of gypsum, it loses its crystallization waters at around $100^{\circ} \mathrm{C}$ [42] and can be transformed to the hemihydrate form and/or to anhydrite III.

Corundum $\left(\alpha-\mathrm{Al}_{2} \mathrm{O}_{3}\right)$ is formed from metastable phases of alumina at temperatures higher than $1000-1200^{\circ} \mathrm{C}[43,44]$. Some $\mathrm{Al}$ and $\mathrm{O}$ areas were detected by SEM-EDS in skeletal crystallites (see Fig. 2) but without showing Raman features. It must be pointed out that when alumina is heated at temperatures below $1100^{\circ} \mathrm{C}$, the formed materials [45] do not exhibit Raman bands [44]. Therefore, those areas could be crystallized under $1100^{\circ} \mathrm{C}$ during fast cooling processes. To confirm the absence of Raman signals of those crystallites, an area of $200 \times 200 \mu \mathrm{m}$ of the crystallites was measured by Raman image, without finding the characteristic bands around 413-416 $\mathrm{cm}^{-1}$ of corundum.

Regarding titanium oxides, it is worth pointing out that rutile (the high temperature mineral phase) was only detected in the inner part. This fact could indicate the differences of temperatures suffered by the different parts of the LDG.

Some authors state that high velocity impacts on Earth are able to generate high temperature melted material that can be subsequently ejected away from the crater and quenched as natural glasses [46]. Others mention that these LDGs quenched from high 
temperatures ranging from 1700 to $2100^{\circ} \mathrm{C}[2,12]$. Therefore, they agree with our results.

Finally, the formation of some other compounds depends on both temperature and pressure. This is the case of calcium carbonate. This compound occurs in five different crystalline polymorphs at ambient pressure and temperature: anhydrous phases (calcite, aragonite, and vaterite), and hydrated phases (monohydrocalcite and ikaite). However, there are also several amorphous forms. Metastable disordered calcium carbonate is transient and transforms into one of the crystalline forms in presence of water or when heated [47]. Below $1200^{\circ} \mathrm{C}$ and approximately at $10 \mathrm{GPa}$, the metastable disordered (amorphous) calcite in the melt could be the precursor of the aragonite enclosed in the glass. Then, a rapid cooling and decrease of temperature could transform this aragonite to calcite, stable at ambient conditions [48, 49]. Besides, aragonite could transform to calcite with time, and it becomes more stable than calcite only at high pressure (approximately $350 \mathrm{MPa}$ at $25^{\circ} \mathrm{C}$ and $700 \mathrm{MPa}$ at $300^{\circ} \mathrm{C}$ ) [50]. Also, it must be taken into account that calcite and aragonite may come from the original substrate materials.

In addition, the signals obtained in the analysis of the matrix were also indicative of the temperature and pressure suffered by the LDGs. Colomban et al. [51-53] used the Raman intensity of these broad bands to determine the degree of crystallisation of amorphous/crystalline silicate glasses as well as their temperatures of formation [5153]. They defined the Polymerization index $\left(\mathrm{I}_{\mathrm{p}}\right)$ as the ratio of the areas under the broad bending band (around $500 \mathrm{~cm}^{-1}$ ) and the stretching band (around $1000 \mathrm{~cm}^{-1}$ ) of the silicate group, because that ratio is strongly correlated to the processing temperature 
470 53], two ranges of index were determined in the LDG matrix spectra. In the matrix 471 spectrum $A$, $\mathrm{I}_{\mathrm{p}}$ was in the range of 6.1-6.8 $(<7)$, typical of glasses formed at 600$4721400^{\circ} \mathrm{C}$, whereas in the matrix spectrum $B, I_{p}$ was in the range of $10.2-16.9$, which corresponds to glass formation temperature higher than $1400^{\circ} \mathrm{C}$. These two different Raman responses in the matrix structure of the studied LDGs suggest that the melt was subjected to two different ranges of temperatures: 600$1400^{\circ} \mathrm{C}$ and higher than $1400^{\circ} \mathrm{C}$ reflecting different polymerization of the melt. Moreover, the compounds found allowed us to know that higher temperatures affected the specimens. The most meaningful data was that rutile, the compound that needs a high temperature to form, was only identified in the inner parts. Besides, shocked zircon, which needs temperatures higher than $1400{ }^{\circ} \mathrm{C}$, was in the inner part as well. In contrast, temperatures around $1470^{\circ} \mathrm{C}$ were also found in the surface due to the presence of $\alpha$-cristobalite.

A specific case mentioned before was the case of an idiomorphic zircon within $\alpha$-cristobalite. This finding could indicate that zircon could be earlier in the crystallization than cristobalite (see Fig. 3a). The zircon was formed by pressure, since if the zircon Raman peak had been displaced by temperatures around $1470^{\circ} \mathrm{C}$ as the same time as cristobalite, they would have had the same crystallization grade. Besides, if the cristobalite had been present in the inclusion when the zircon was formed at 20 GPa, its Raman bands would have been changed [54]. Therefore, this discovery proves that this inclusion experimented a high pressure episode and, later, an increase of temperature.

The high pressure conditions in the formation of the LDGs were also corroborated by the presence of coesite (high-pressure polymorphs of quartz), aragonite, amorphous calcite and displaced quartz, all of them only found in the inner part. 
Therefore, it could be thought that only the core of the studied specimens was subjected to high pressures, which is not logic. Moreover, low pressure or settled state compounds appeared all over the samples. For instance, the shape of the tiny size and morphology of the crystallites detected in the inner matrix (Fig. 2) can be explained by a high degree of undercooling process (become supercooled) during the crystal formation.

An impact process is a wide but rapid process that implies different physical processes which promote very high pressure and temperature conditions during the formation of the melts. After the impact, the pressure conditions drop but the temperature conditions would maintain in part to support the molten material. As the impact process progress, melt fragments can trap minerals and rock debris at a given temperature and pressure, and consequently the Raman signatures of such materials will reflect the different shock and thermal conditions. Hence, the accumulation of high pressure and temperature minerals in the inner parts of the recovered LDGs could be explained if we consider that the LDGs started at high pressure (more than $30 \mathrm{GPa}$ ) and temperature (more than $1470^{\circ} \mathrm{C}$ ) conditions after the first impact, flying short distances

510 (unlike tektites). Then each melt fragment could undergone a second collision event while cooling, trapping more materials (at low pressure but intermediate temperature, i.e. $600-1400^{\circ} \mathrm{C}$ ) from the terrestrial surface.

Moreover, regarding gypsum, on one side, we may assign its bands to normal gypsum according to bibliography [55]. It would have adhered from the soil to the LDG

515 surface after the impact during the cooling or whenever in the LDG existence. On the 516 other hand, Knittle et al. [56] assigned its $1006 \mathrm{~cm}^{-1}$ Raman peak to low pressure 517 (around $6 \mathrm{GPa}$ ) gypsum. In both cases the gypsum could be trapped during the 518 successive impacts after the first one. It is also conceivable that the pressures of these 519 subsequent impacts would have been much lower and therefore, the Raman bands 
would appear more displaced according to the bibliography. In addition, gypsum appeared with cristobalite, which involves high temperatures $\left(1470^{\circ} \mathrm{C}\right)$ but gypsum starts to lose the crystallization waters at around $100^{\circ} \mathrm{C}$ [42], then it could be trapped after the first impact (formation of cristobalite at high temperature). Other option could be the formation of gypsum as a secondary product from a soluble anhydrite hydration with time, given the long period from LDG formation and the cracks and fissures connected to the surface of the glass, which would explain the presence of water of crystallization in the interior of the LDG. This anhydrite could be terrestrial or preterrestrial, and could be formed either by the reaction of the LDG superficial carbonates and the atmospheric $\mathrm{SO}_{\mathrm{x}}$, or by extreme heating from a previous gypsum trapped during the first impact as well.

It is difficult to say which compound was the precursor, gypsum, anhydrite or maybe both. According to previous works [6], anhydrite was seen in white deposits inside the sand of the Libyan Desert. For that reason, the anhydrite found in the LDG samples could belong to these latest deposits. The same situation could have happened with gypsum, which could be also present in the substrate [57].

In relation to the temperature, the distribution to the anhydrites found in the LDGs is rather reasonable. A-I, stable above $1180{ }^{\circ} \mathrm{C}$, was identified inside where it could have been formed by the high temperatures of the impact. A-II, stable from 300 to $1180{ }^{\circ} \mathrm{C}$, was detected in the surface of the LDG, possibly formed in a cooling process but still remaining partially melted and with capacity to trap materials [6].

Concerning carbon, Kramers et al. [20] found carbon phases with G broad band at a high wavenumber $\left(1597 \mathrm{~cm}^{-1}\right)$ in a stone called "Hypatia", sampled from the same area of LDG. Those authors considered that stone being a remnant of a cometary nucleus fragment that it could have been part of a bolide that formed the LDG. In our 


\section{7}

case, the Raman bands suggested amorphous carbon, which is typical from sedimentary rocks [2]. However, it is noteworthy that Abate et al. [58] did not find traces of carbon in the target rocks of the LDG area.

Finally, important data can be extracted from the found cavities and embedded bubbles. The identification of olivine and pyroxene has not been mentioned in this type of samples so far.

Vesicles could have been trapped during boiling of geothermal/hydrothermal fluids. The vesicles indicate that there were gas bubbles in the melt when it solidified. Gaseous vesicles could have been formed in the melt with a decrease of the solubility of dissolved gases, due to changes of the physical conditions (temperature, pressure and oxygen fugacity). Therefore, the formation of gases and fluid bubbles should have occurred during the impact process. The contact with the terrestrial atmosphere could have also introduced terrestrial heavy noble gases to the samples [59]. During this event, volatiles from the target rocks, water from the pores or fractures water, nitrogen and organics could be released. If pressure was elevated, water and nitrogen could dissolve in the liquids and upon pressure decrease, water and nitrogen soon degassed again, leaving trapped bubbles after solidification [34,60]. After the impact, when the bubbles were already formed, the temperature should have been lower than $1600^{\circ} \mathrm{C}$, because above it, the bubbles would disappear [16].

Apart from all this about the mineral distribution hypothesis in the LDGs, it should be taken into account that the surface of the LDGs could not be the original and belongs to the inner part of a bigger fragment that has been eroded with time.

\section{CONCLUSIONS}



determine the effect of the pressure and temperature. The identification of compounds related to high and low temperatures and pressures allowed us to know the temperatures and pressures at which samples could be subjected (from 300 to $>1470^{\circ} \mathrm{C}$, and from 10 to >30 Gpa). The compounds belonging to high pressure and temperature could be

574 formed during the meteorite/asteroid impact or airburst, and subsequently, with the cooling, mineral phases corresponding to low pressure and temperature crystallized. Moreover, if the impact process had progressed (flying short distances), melt fragments could have trapped other minerals from the terrestrial surface until just before the end of the cooling process. In general, the cooling of the different areas of the LDG could have been heterogeneous and, as a consequence its mineral distribution too. It should be also highlighted that the LDG surface may not be the original and belong to the inner part of a bigger fragment. recognized, such us microcline feldspar, coesite, corundum, calcite, amorphous calcite, magnesite, gypsum, cinnabar, hematite, limonite, fosterite, enstatite, tephroite and nitrogen and oxygen gases.

\section{ACKNOWLEDGMENTS}

This work has been funded by the Spanish Ministry of Economy and

Competitiveness and FEDER, the European Development Regional Fund

590 "Development of the RAMAN instrument for the ESA EXOMARS Mission: Science development, Prototype Tests and Operation” project (Ref. ESP2014-56138-C3-2-R) 
594

595

596

597

598

599

600

601

602

603

604

605

606

607

608

609

610

611

612

613

614

615

616 Desert Glass: Inherited Pan-African age signatures and new evidence for target material, 617 Meteorit Planet Sci. 2002; 37: 565-76.

Laboratory of the SGIker (UPV/EHU, MICINN, GV/EJ, ERDF and ESF) is gratefully acknowledged. The wholehearted technical support of Iñaki Aretxaga with the holders to the equipments is also appreciatively acknowledged.

(1)

\section{Conflict of interest}

The authors declare that they have no conflict of interest.

\section{REFERENCES}

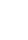

[1] Clayton PA, Spencer LJ, Silica-Glass from the Libyan Desert, Mineral Mag. 1934; 23:501-8.

[2] Pratesi G, Viti C, Cipriani C, Mellini M, Silicate-silicate liquid inmiscibility and graphite ribons in Libyan desert glass, Geochim Cosmochim Acta. 2002; 66: 903-11.

[3] Swaenen M, Stefaniak EA, Frost R, Worobiec A, Van Grieken R, Investigation of inclusions trapped inside Libyan Desert glass by Raman microscopy, Anal Bioanal Chem. 2010; 397: 2659-65.

[4] Barrat JA, Jahn BM, Amosse J, Rocchia R, Keller F, Poupeau GR, Diemer E, Geochemistry and origin of Libyan Desert glasses, Geochim Cosmochim Acta. 1997; 61:1953-59.

[5] Koeberl C, Libyan Desert Glass: geochemical composition and origin, Proceedings of the “Silica `96” Meeting, Pyramids Segrate, Milano, 1997.

[6] Schaaf P, Müller-Sohnius D, Strontium and neodymium isotopic study of Libyan 
618 [7] Aboud T, Libyan Desert Glass: has the enigma of its origin been resolved?, Physics 619 Procedia 2009; 2: 1425-32.

620 [8] Storzer D and Wagner GA, Fission-track dating of meteorite impacts, Meteoritics

621

622

623

624

625

626

627

628

629

630

631

632

633

634

635

636

637

638

639

640

641 1977; 12: 368-369.

[9] Ramirez-Cardona M, El-Barkooky A, Hamdan M, Flores-Castro K, JimenezMartinez NI, Mendoza-Espinosa M, On the Lybian Desert Silica Glass (LDSG) transport model from a hypothetical impact structure, International Geological Congress (IGC), Oslo. 2008, PIS-01 (abstr.).

[10] Jimenez-Martinez N, Ramirez M, Diaz-Hernandez R, Rodriguez-Gomez G, Fluvial Transport Model from Spatial Distribution Analysis of Libyan Desert Glass Mass on the Great Sand Sea (Southwest Egypt): Clues to Primary Glass Distribution, Geosciences 2015; 5: 95-116

[11] Horn P, Müller-Sohnius D, Schaaf P, Kleinmann B, Storzer D, Potasium -argon and fission-track dating of Libyan Desert Glass, and strontium- and neodymium isotope constraints on its source rocks. In Proc. "Silica 96”, Meeting on Libyan Desert Glass and Related Events (ed. V. de Michele) 1997:59-76.

[12] Greshake A, Koeberl C, Fritz J, Reimold WU, Brownish inclusions and dark streaks in Libyan Desert Glass: Evidence for high-temperature melting of the target rock, Meteorit Planet Sci. 2010; 45: 973-89.

[13] Kleinmann B, Horn P, Langehorst F, Evidence for shock metamorphism in sandstones from the Libyan Desert Glass strewn field, Meteorit Planet Sci. 2001; 36: 1277-82.

[14] Seebaugh WR, Strauss AM, A cometary impact model for the source of Libyan Desert glass, J. Non-Crystalline Solids, 1984; 511-519. 
642 [15] Koeberl C, Libyan Desert Glass: formation by meteorite impact or airburst? 23 ${ }^{\text {rd }}$

643 Colloquium of African Geology (CAG), South Africa, 2011, \#7 (abstr.)

644 [16] Boslough MBE, Crawford DA, Low-altitude airbursts and the impact threat, Int J 645 Impact Eng. 2008; 35: 1441-48.

646 [17] Giuli G, Paris E, Pratesi G, Koeberl C, Cipriani C, Iron oxidation state in the Fe647 rich layer and silica matrix of Libyan Desrt Glass: A high- resolution XANES study, 648 Meteorit Planet Sci. 2003; 38: 1181-86.

649

[18] Murali A, Zolensky ME, Underwood JR Jr, Giegengack RF Chondritic debris in

650

Libyan Desert Glass. In: Proceedings, Silica 96, Meeting, ed De Michele V. Milan:

651 Pyramids 1997; 133-142

652 [19] Rocchia R, Robin E, Fröhlich F, Meon H, Frogent L, Diemer E, L’origine des 653 verres du désert libyque: un impact météorique. Comptes Rendus de l’Académie des 654 Sciences 1996; 322: 839-845.

655 [20] Kramers JD, Andreoli MAG, Atanasova M, Belyanin GA, Block DL, Franklyn C, 656 Harrisf C, Lekgoathi M, Montross CS, Ntsoane T, Pischedda V, Segonyane P, (Fanus) Viljoen KS, Westraadt JE, Unique chemistry of a diamond-bearing pebble from the Libyan Desert Glass strewnfield, SW Egypt: Evidence for a shocked comet fragment, 659 Earth Planet Sc Lett. 2013; 382: 21-31.

660 [21]Earth Observatory of NASA:

661 http://earthobservatory.nasa.gov/IOTD/view.php?id=6351

662 [22] Irazola M, Olivares M, Castro K, Maguregui M, Martinez-Arkarazo I, Madariaga 663 JM, In situ Raman spectroscopy analysis combined with Raman and SEM/EDS imaging 664 to assess the conservation state of 16th century wall paintings, J Raman Spectrosc. 665 2012; 43: 1676-84. 
666

667

668

669

670

671

672

673

674

675

676

677

678

679

680

681

682

683

684

685

686

687

688

689

[23] Castro K, Pérez-Alonso M, Rodríguez-Laso MD, Fernández LA, Madariaga JM, On-line FT-Raman and dispersive Raman spectra database of artists' materials (eVISART database), Anal Bioanal Chem. 2005; 382: 248-58.

[24] Lafuente B, R.T. Downs, H. Yang, N. Stone, The power of databases: the RRUFF project. In: Highlights in Mineralogical Crystallography (eds. T. Armbruster and R. M. Danisi). Berlin, 2015, pp 1-30.

[25] Gucsik A, Koeberl C, Brandstätter F, Libowitzky E, Zhang M, Infrared, Raman and cathodoluminescence studies of impact glasses, Meteorit Planet Sci. 2004; 39: 1273-85.

[26] Aramendia J, Gomez-Nubla L, Fdez-Ortiz de Vallejuelo S, Castro K, Murelaga X, Madariaga JM, New findings by Raman micro spectroscopy in the bulk and inclusions trapped in Libyan Desert Glass, Spectrosc Lett. 2011; 44: 521-25.

[27] Magna T, Deutsch A, Mezger K, Skala R, Seitz HM, Mizera J, Randa Z, Adolph L, Lithium in tektites and impact glasses: Implications for sources, histories and large impacts, Geochim Cosmochim Acta. 2011; 75: 2137-58.

[28] Faulques E, Fritsch E, Ostroumov M, Spectroscopy of natural silica-rich glasses, J. Miner Petrol Sci. 2001; 96: 120-28.

[29] Lofgren GE, Experimental studies on the dynamic crystallization of silicate melts. In: Physics of Magmatic Processes (Ed. Hargraves, R.B.) Princeton University Press, New Jersey, 1980, pp. 487-551.

[30] Kobayashi T, Hirajima T, Hiroi T, Svojtka M, Determination of $\mathrm{SiO}_{2}$ Raman spectrum indicating the transformation from coesite to quartz in Gfohl migmatitic gneisses in the Moldanubian Zone, Czech Republic, J Miner Petrol Sci. 2008; 103 : $105-11$. 
[31] Prieto-Taboada N, Gomez-Laserna O, Martínez-Arkarazo I, Olazabal MA,

Madariaga JM, Raman Spectra of the Different Phases in the $\mathrm{CaSO}_{4}-\mathrm{H}_{2} \mathrm{O}$ System, Anal

692 Chem. 2014; 86: 10131-37.

693

[32] Ferrari AC, Robertson J, Interpretation of Raman spectra of disordered and amorphous carbon, Phys Rev. B 2000; 61: 14095-107.

[33] Buric MP, Gas phase raman spectroscopy using hollow waveguides, Ph. D. thesis, 696 University of Pittsburgh, 2010.

697

[34] Perron C, Fiéni C, Guilhaumou N, Nitrogen and water bubbles, oxygen isotopes,

698 shock effects: Deciphering the history of the Bencubbin meteorite breccias, Geochim Cosmochim Ac. 2008; 72: 959-77.

[35] Anbarasan PM, Senthil Kumar P, Vasudevan K, Moorthy Babu S, Aroulmoji V,

DFT and TD-DFT Calculations of Some Metal Free Phthalonitrile Derivatives for 702 Enhancement of the Dye Sensitized Solar Cells, Ac Phys Polonica A 2011; 119: 395404.

704

[36] McMillan PF, Wolf GH, Lambert P, A Raman Spectroscopic Study of Shocked 705 Single Crystalline Quartz, Phys Chem Miner. 1992; 19: 71-9.

[37] Sighinolfi GP, Elmi C, Serra R, Contini G, High density silica phases as evidence 707 of small-scale hypervelocity impacts: the Gebel Kamil Crater (Egypt), Period Mineral. 2014; 83: 299-312.

[38] Henderson T, Milam KA, XRD analyses of silurian dolostones from the central

710 uplift of the Kentland impact structure, Planet. Sci. XCVI. Lunar Planet. Inst., Newton 711 County. 2015, \#2989 (Abstract).

[39] Keil K, Stoeffler D, Love SG, Scott ERD, Constraints on the role of impact heating and melting in asteroids, Meteorit. Planet. Sci. 1997; 32, 349-363. 
714

715

716

717

718

719

720

721

722

723

724

725

726

727

728

729

730

731

732

733

734

735

736

737

[40] Zhang M, Salje EKH, Farnan I, Graeme-Barber A, Daniel P, Ewing RC, Clark

AM, Leroux H, Metamictization of zircon: Raman spectroscopic study, J Phys Condens Mat. 2000; 12: 1915-25.

[41] Barnes P, Bensted J, Structure and Performance of Cements. Second Edition, Spon Press, New York, 2002.

[42] Prasad PSR, Pradhan A, Gowd TN, In situ micro- Raman investigation of dehydration mechanism in natural gypsum, Curr Sci. 2001; 80: 1203-7.

[43] Wang Y, Suryanarayana C, An L, Phase Transformation in Nanometer-Sized $\gamma$ Alumina by Mechanical Milling, J Am Ceram Soc. 2005; 88: 780-3.

[44] Kadleíková M, Breza J, Veselý M, Raman spectra of synthetic sapphire. Microelectr J. 2001; 32: 955-8.

[45] Souza Santos P, Souza Santos H, Toledo SP, Standard Transition Aluminas. Electron Microscopy Studies, Mater Res. 2000; 3: 104-14.

[46] Dressler BO, Reimold WU, Terrestrial impact melt rocks and glasses, Earth-Sci. Rev. 2001; 56, 205-284.

[47] Radha AV, Forbes TZ, Killian CE, Gilbert PUPA, Navrotsky A, Transformation and crystallization energetics of synthetic and biogenic amorphous calcium carbonate, $\mathrm{P}$ Natl Acad Sci. 2010; 107: 16438-43.

[48] Black L, Breen C, Yarwood J, Garbev K, Stemmermann P, Gasharova B, Structural features of C-S-H(I) and its carbonation in air - a Raman spectroscopic study. Part II: carbonated phases, J Am Ceram Soc. 2007; 90: 908-17.

[49] Suito K, Namba J, Horikawa T, Taniguchi Y, Sakurai N, Kobayashi M, Onodera A, Shimomura O, Kikegawa $\mathrm{T}$, Phase relations of $\mathrm{CaCO}_{3}$ at high pressure and high temperature, Am Mineral. 2001; 86: 997-1002. 

Technology 3. 10th ed., New York, 2007.

[51] Colomban P, Raman spectroscopy in archaeology and art history, Case study: glasses, glazes and ceramics: recognition of ancient technology from the Raman spectra. In Raman spectroscopy in archaeology and art history (eds H. G. M. Edwards \& J. M. Chalmers), New York, 2000, pp. 192-206.

[52] Colomban P, Polymerization degree and Raman identification of ancient glasses used for jewelry, ceramic enamels and mosaics, J Non Cryst Solids 2003; 323: 180-7. [53] Colomban P, Slodczyk A, Raman intensity: An important tool to study the structure and phase transitions of amorphous/crystalline materials, Opt Mater. 2009; 31: 1759-63.

[54] Prokopenko VB, Dubrovinsky LS, Dmitriev V, Weber HP, In situ characterization of phase transitions in cristobalite under high pressure by Raman spectroscopy and Xray diffraction, J Alloy Compd. 2001; 327: 87-95.

752 [55] Edwards HGM, Sadooni F, Vitek P, Jehlicka J, Raman spectroscopy of the Dukhan sabkha: identification of geological and biogeological molecules in an extreme environment, Philos Trans Roy Soc A 2010; 368: 3099-107. [56] Knittle E, Phillips W, Williams Q, An infrared and Raman spectroscopic study of gypsum at high pressures, Phys Chem Miner. 2001; 28: 630-40. Evolution II: Geol S Am S. 1999; 339: 177-92. 
761 [59] Crozaz G, Wadhwa M, The terrestrial alteration of Saharan Shergottites Dar al

762 Gani 476 and 489: A case study of weathering in a hot desert environment, Geochim 763 Cosmochim Acta 2001; 65: 971-8.

764 [60] Blamey NJF, Composition and evolution of crustal, geothermal and hydrothermal

765 fluids interpreted using quantitative fluid inclusion gas analysis, J Geochem Explor. $766 \quad 2012 ; 116-117:$ 17-27. 